(C) 1982 ISIJ

\title{
統計理論のコークス炉装入炭粒度調整技術への応用
}

\section{Application of Statistic Theory to the Size Preparation of Coal Charge}

\section{Hidetaka Sugrnobe and Tsugio Mryagawa}

Synopsis :

For the purpose of obtaining the maximum coke strength by optimum size preparation of coal charge, a mathematical theory is developed, which clarifies the relation between coke strength, inhomogeneity of charge and grain size structure of charge.

Inhomogeneity of charge is represented by variance $(V)$ of caking property parameter $(X)$ and of coal rank parameter $(Y)$, and related to observed coke strength $(S)$ by the following equation,

$$
S=S+\frac{1}{2} \partial^{2} S X^{2} V_{\mathrm{xx}}+{ }_{\partial X} \partial^{2} S Y V_{\mathrm{xy}}+\frac{1}{2} \partial^{2} S Y^{2} V_{y y}
$$

where $S$ is coke strength of homogeneous charge. Furthermore the mathematical solution is derived for each variance, which is expressed by volume and coking properties of each coal particle.

The preliminary analysis of coke strength shows that the second derivatives are always negative. The mathematical solution shows that the variance is effectively lowered by the selective fine crushing of coal.

The validity of theory is examined by experiments. For practical purposes, the theoretical equation is approximated based on the experimental results.

\section{1. 緒言}

装入炭の細粉化がコークス組織の均質性を高め, コー クス強度の问上に㕮果的なことはよく知られているが, 過度の微粉化には幾つかの欠点もあり, 実際には装入炭 の粒度水潐は一定範囲に留めざるを得ない。すなわち，

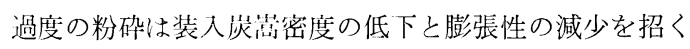
ので粒子間の融着が阻書され, 時としてコークス強度を 低下させることがある。李た䓟密度の減少はコークス炉 の生産性を低卜させる。

このため, 微粉砕がコークス強度の向上に効果的な石 炭活ど細粒化し，そうでない炭種は比較的粗粒のままと するといら力向で粒度調整が行われている. しかし現行 の粒度調整法は定性的な考方方に立脚するものであり， 美浦 ${ }^{1)}$ が指摘しているよらに統一的な粒度調整理論はい まだ笔成していない，この理由は, 装入炭の均質性の定 義があいまいのま使用されてきたためと考兄られる。

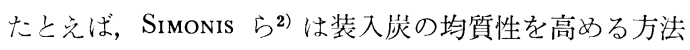
として, 各配合種の衣面積を同一とする粒度調整法を提 呾したが，均質性が理論的に定義されていない現状で は，彼らの方法でぞれだけの均質化がなされるかは不明 である.

今回, コークス強度と装入炭の均質性および粒度構成
との一般的関係を理論化し, 一般的な粒度調整理論を構 築したので報告する.

\section{2. 理論}

\section{$2 \cdot 1$ 前提条件}

コークス強度に関して一般的に認められた経験則3)を

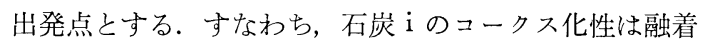
性パラメータ $\left(X_{\mathrm{i}}\right)$ と石炭化度パラメータ $\left(Y_{\mathrm{i}}\right)$ で規定 され，また配合炭のコークス強度 $(S)$ は両パラメータ の加重平均值, $\bar{X}$ と $Y$ で決定されるとする． $F_{\text {io }}$ を各石 炭の重量配合率, $n$ を配合種の総数とすると, 次式で前 提条件が表される.

$$
\begin{aligned}
& S \equiv S(\bar{X}, \bar{Y}) \ldots \ldots \ldots \ldots \ldots \ldots \\
& \bar{X}=\sum_{\mathrm{i}=1}^{n} F_{\mathrm{i} 0} X_{\mathrm{i}}, \quad Y=\sum_{\mathrm{i}=1}^{n} F_{\mathrm{i} 0} Y_{\mathrm{i}}
\end{aligned}
$$

\section{$2 \cdot 2$ コークス強度と装入炭の不均質性の関係}

通常測定されるコークス強度とは, 確率的な意味にお いて装入炭の各部分から得られるコークスの強度の平均 值である. そこで, 装入炭を仮想的に同一重量で $N$ 個に 分割し, $\mathrm{j}$ 番目のブロックから得られるコークスの強度 を $S_{\mathbf{j}}$ としよう。この時, 実測強度 $(\bar{S})$ は次式で与兄 られる. 


$$
\bar{S}=\frac{1}{N} \sum_{\mathrm{j}=1}^{N} S_{\mathrm{j}}
$$

ここで $\mathrm{j}$ 番目のブロックに注目すると，この部分におけ る性状は装入炭の平均值 $(\bar{X}, \bar{Y})$ からある偏差を有した $\left(\bar{X}+\Delta X_{\mathrm{j}}, \bar{Y}+\Delta Y_{\mathrm{j}}\right)$ の值となつており, 強度 $S_{\mathrm{j}}$ は次式 で与えられる.

$$
S_{\mathrm{j}}=S\left(\bar{X}+\Delta X_{\mathrm{j}}, \quad \bar{Y}+\Delta Y_{\mathrm{j}}\right)
$$

上式を $(\bar{X}, \bar{Y})$ 近傍でテーラー展開して, 2 次項まで をとり，(3)式に代入すると，

$$
S=S+\frac{1}{2} \frac{\partial^{2} S}{\partial X^{2}} V_{\mathrm{XX}}+\frac{\partial^{2} S}{\partial X \partial Y} V_{\mathrm{XY}}+\frac{1}{2}{ }_{\partial Y^{2}}^{\partial^{2} S} V_{\mathrm{YY}}
$$

ここに, $V$ 項は次式で定義される.

$$
\begin{aligned}
& V_{\mathrm{XX}}=\frac{1}{N} \sum_{\mathrm{j}=1}^{N}\left(\Delta X_{\mathrm{j}}\right)^{2} \\
& V_{\mathrm{XY}}=\frac{1}{N} \sum_{\mathrm{j}=1}^{N} \Delta X_{\mathrm{j}} \Delta Y_{\mathrm{j}} \\
& V_{\mathrm{YY}}=\frac{1}{N} \sum_{\mathrm{j}=1}^{N}\left(\Delta Y_{\mathrm{j}}\right)^{2}
\end{aligned}
$$

（5）式の意味は次のように解釈される，仮に装入炭各部 の性状が同一であれば $S$ は $S$ と一致するので， $S$ は装入 炭が均質な時の強度を表すＶ $V$ 項は強度因子の分散であ り，装入炭の不均質性をコークス化性パラメータで表現 したものである。また 2 次偏微分係数值は装入炭の性状 $(\bar{X}, \bar{Y})$ で決定されるから，コークス強度に対する不均 質性の効果が装入炭性状に依存することがわかる。

\section{$2 \cdot 3$ 装入炭の不均澌性と粒度構成の関係}

装入炭の不均質性の起源は混合過程と粒度構成に求め られる。しかし実際の配合過程を考えてみると混合は十 分に留意して行われており，また混合操作の改良が細粒 化よりもコークス強度の向上に有効であるという報告は 見当たらない，このことから，装入炭の混合は十分に進 行して各石炭粒子は統計的に分布しており，不均質性は 粒度構成に起因するものと考えられる。

BUSLIK $^{4)}$ は一定体積中に含まれる特定粒径の粒子の濃 度を対象とし，その分散の一般解を求めた．BUSLIK の考 え方を拡張すると，（5)式中の分散項は石炭の性状と粒 子体積で表される，簡単のために，石炭の密度は炭種に よらず一定であり，石炭 $\mathrm{i}$ は単一の粒子体積 $v_{\mathrm{i}}$ を有す ると仮定し，Iを1ブロックに含まれる石炭の体積とす ると次式を得る (Appendix 参照).

$$
V_{\mathrm{XX}}=\frac{1}{I} \sum_{\mathrm{i}=1}^{n} F_{\mathrm{io}} v_{\mathrm{i}}\left(\bar{X}-X_{\mathrm{i}}\right)^{2}
$$

$$
\begin{aligned}
& V_{\mathrm{XY}}=\frac{1}{I} \sum_{\mathrm{i}=1}^{n} F_{\mathrm{io}} v_{\mathrm{i}}\left(\bar{X}-X_{\mathrm{i}}\right)\left(\bar{Y}-Y_{\mathrm{i}}\right) \\
& V_{\mathrm{YY}}=\frac{1}{I} \sum_{\mathrm{i}=1}^{n} F_{\mathrm{io}} v_{\mathrm{i}}\left(\bar{Y}-Y_{\mathrm{i}}\right)^{2} \ldots \ldots \ldots \ldots \ldots
\end{aligned}
$$

実際の粉厒炭は粒度分布を有し，また同一の石炭であ つても粒径によつて性状は異なる。したがつて，石炭粒 子が球形であると仮定すれば，(9)〜(11)式は次のよう に一般化される.

$$
\begin{aligned}
& V_{\mathrm{XX}}=\frac{\pi}{6 I} \sum_{\mathrm{i}=1}^{n} F_{\mathrm{io} o} \int_{0}^{\infty} f_{\mathrm{i}}(r) r^{3}\left\{\bar{X}-X_{\mathrm{i}}(r)\right\}^{2} d r \ldots \\
& V_{\mathrm{XY}}=\frac{\pi}{6 I} \sum_{\mathrm{i}=1}^{n} F_{\mathrm{io}} \int_{0}^{\infty} f_{\mathrm{i}}(r) r^{3}\left\{\bar{X}-X_{\mathrm{i}}(r)\right\} \\
& \cdot\left\{\bar{Y}-Y_{\mathrm{i}}(r)\right\} d r \ldots \ldots \ldots \ldots \ldots \ldots \ldots \ldots \ldots \ldots \ldots \ldots \ldots \ldots \ldots \ldots \ldots \\
& V_{\mathrm{YY}}=\frac{\pi}{6 I} \sum_{\mathrm{i}=1}^{n} F_{\mathrm{io}} \int_{0}^{\infty} f_{\mathrm{i}}(r) r^{3}\left\{\bar{Y}-Y_{\mathrm{i}}(r)\right\}^{2} d r
\end{aligned}
$$

ここに, $r$ : 石炭粒径, $f(r)$ : 微分型粘度分市関数, $X$ $(r)$ : 直径 $r$ の粒子の $X$ 值, $Y(r)$ : 值径 $r$ の粒子の $Y$ 值であり, $f(r)$ は次式で規格化されている.

$$
\int_{0}^{\infty} f_{\mathrm{i}}(r) d r=1
$$

\section{3. 理論式の解釈}

前章で述べた理論は $(1)$ ，（2)式で䘚される単純な経 験則を出発点としている. そこで，このコークス強度に 関する経験則を踏をえて理論式の具体的な意味を解釈し よう．最初に(5)式中で分散項とコークス強度を結びつ けている偏微分係数について検討する. 以下，具体的に 論じるときは， $X$ として最高流動度対数值 $(\mathrm{MF}), Y$ と してビトリニットの平均最高反射率 $\left(R_{0}\right)$ を用いる.

宮津 $5^{5)}$ は，コークス強度 $\mathrm{DI}_{15}^{30}$ と装入炭性状の関係 を調查し， $R_{0}$ が一定值の場合， $\mathrm{DI}_{15}^{30}$ は $\mathrm{MF}$ の增加に つれて上昇するが，やがて飽和する傾问にあることを示 した.この結果は実測強度 $S$ に関するものであるが， $S$ も同様に振舞うことは容易に想像できる.なぜならば, 粒度調整の差異よりも装入炭性状の差異が $\mathrm{DI}_{15}^{30}$ に大き く寄与することはよく知られており，この経験から(5) 式中の分散項の寄与は比較的小さいと判断されるからで ある. $S$ が $X$ に対して指数関数的に増加, 飽和寸る挙動 を模式的に Fig. 1 に示す。この時, $\partial S / \partial X$ は単調に減 少し，その減少幅は徐々に小さくなる.したがつて, $\partial^{2} S / \partial X^{2}$ は常に負值であり，その絶対低は $X$ が小さい時 ほど大きい.

$\mathrm{DI}_{15}^{30}$ と $R_{0}$ の関係を Fig. 2 に示す. Fig. 2 は千葉 


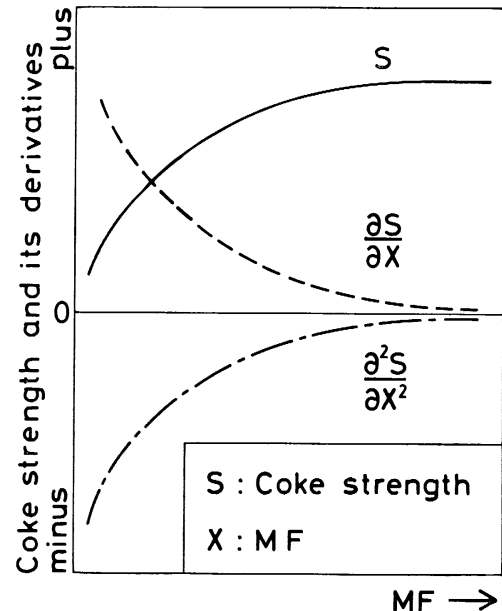

Fig. 1. Schematic representation for influence of maximum fluidity (log ddpm) of charge on coke strength and its derivatives.

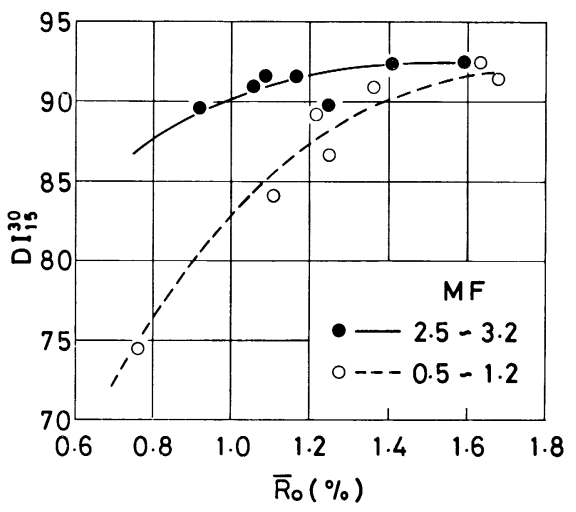

Fig. 2. Relation between coke strength and reflectance of vitrinite (results of single coal coking in $250 \mathrm{~kg}$ test ovens).

工場入荷炭（昭和 52 年 4 月〜 54 年 3 月）の $250 \mathrm{~kg}$ 試 験炉による単味炭乾留試験の結果を整理したものであ る. $\bar{R}_{0}$ に刘しても $\mathrm{DI}_{15}^{30}$ は指数関数的に増加, 飽和す る. したがって $\partial^{2} S / \partial Y^{2}$ は常に負值であり,その絶対值 はYが小さい時ほど大きい。 また，ある一定の $R_{0}$ 值で の $\mathrm{MF}$ 增加による強度向上分, すなわち $\partial S / \partial X \cdot \Delta X$ は $R_{0}$ の増加にともなつて徐々に減少することがわかる. したがって $\partial^{2} S / \partial X \partial Y$ も掌に負值であり， $X, Y$ 值が大 になるにつれて 0 に近づく。

このように偏微分係数值はすべて負值であるので，装 入炭の不均質がュークス強度に負効果を与兄ることがわ かる. また，装入炭の品位が劣る時ほど偏微分係数の絶 対值が大なので, 強度に対する不均質性の効果が顕著と なる、 $V_{\mathrm{XY}}$ が負值の時の見掛け上の強度向上効果は, 融
着性の不足した部分では高い石炭化度で，石炭化度の低 い部分では良好な融着性で強度低下が補償されているこ とを表している。

一般的な粒度調整の指針は，(9)〜 (11) 式から得られ る.すなわら一般に細粒化を行えば不均質性が減少し， コークス強度が向上する. 特に平均性状から大きく異な る性状の炭種の微細化が強度向上に貢献する.

\section{4. 理論式の検証}

\section{$4 \cdot 1$ 単味炭}

簡単のために，融着性が十分で，コークス強度が近似 的に石炭化度のみで規定された場合を考学る．微粉砕時 と粗粉砕時の強度差は, (5), (14) 式から

$$
\begin{gathered}
S_{\mathrm{F}}-S_{\mathrm{C}}=\frac{\pi}{12 I} \frac{\partial^{2} S}{\partial Y^{2}} \int_{0}^{\infty}\left[f_{\mathrm{F}}(r)\left\{\bar{Y}-Y_{\mathrm{F}}(r)\right\}^{2}\right. \\
\left.-f_{\mathrm{C}}(r)\left\{\bar{Y}-Y_{\mathrm{C}}(r)\right\}^{2}\right] r^{3} d r \ldots \ldots \ldots \ldots \ldots \ldots \ldots \ldots \ldots \ldots \ldots \ldots
\end{gathered}
$$

ここに, 添字 $\mathrm{F}$ は微粉砕を, $\mathrm{c}$ は粗粉砕を表す. 石炭化 度パラメータの值は有限であるから， $f_{\mathrm{C}}(r)$ に比べて $f_{\mathrm{F}}(r)$ を十分に小径側に移行させれば上式中の積分は負 となり，微粉砕が強度を向上させることになる。

宮川ら ${ }^{6)}$ は単味炭を同一条件で粉砕して $R_{0}$ と粒径の 関係を調べ，粒径による R。 の変化が炭種によらずほぼ 一定であることを見出した。すなわち， $\bar{Y}-Y_{\mathrm{i}}(r)$ は粉 砕条件によつて定まり，炭種による差は小さい，したが って (16)式中の積分值は粒度構成の変化によつて定まる ので, 単味炭微粉砕時の強度向上は $\partial^{2} S / \partial Y^{2}$ の絶対值に 比例する。また $\partial^{2} S / \partial Y^{2}$ の絶対值は 3 章で述べたように $R_{0}$ に対して指数関数的に減少するから, 強度向上は低 $R_{0}$ 炭ほど大さいことになる.

この理論的予測を確認するために, $250 \mathrm{~kg}$ 試験炉によ る乾留実験を行つた. $\mathrm{DI}_{15}^{30}$ が近似的に $\bar{R}_{0}$ のみの関数 となるように比較的流動性の高い石炭を選び, 各石炭の $3 \mathrm{~mm}$ 目篩下重量 $\%(P)$ が $70,85,100 \%$ となるよう に調整し，乾留コークスの $\mathrm{DI}_{15}^{30}$ を測定した，供試炭の 性状とコークス強度を Table 1 に示す. 微粉砕時の強 度向上分 $\left(3 \mathrm{~mm}\right.$ 穊下 $70 \%$ 時の強度を基準）と $R_{0}$ の 関係を Fig. 3 に示す. $R_{0}$ が小さい時ほど微粉砕効果 が大きく, 実験結果は理論からの子測と一致している.

\begin{tabular}{|c|c|c|c|c|c|c|}
\hline \multicolumn{3}{|c|}{ Coal } & Liddell & $\begin{array}{l}\text { Pittston } \\
\text { Blend }\end{array}$ & $\begin{array}{l}\text { South } \\
\text { Bulli }\end{array}$ & Itmann \\
\hline \multicolumn{3}{|c|}{$\mathrm{MF}(\log$ maximum fluidity) } & 2. 40 & 3.40 & 2.86 & 2. 38 \\
\hline \multicolumn{3}{|c|}{$\bar{R}_{0}(\%)$} & 0.78 & 1.06 & 1. 24 & 1.55 \\
\hline $\mathrm{DI}_{15}^{30}$ & $-3 \mathrm{~mm}$ & $\begin{array}{r}70 \% \\
85 \% \\
100 \%\end{array}$ & $\begin{array}{l}71.9 \\
75.9 \\
80.0\end{array}$ & $\begin{array}{l}89.6 \\
91.2 \\
92.4\end{array}$ & $\begin{array}{l}90.6 \\
91.2 \\
92.7\end{array}$ & $\begin{array}{l}91.4 \\
91.4 \\
91.3\end{array}$ \\
\hline
\end{tabular}

Table 1. Coking properties of coal samples. 


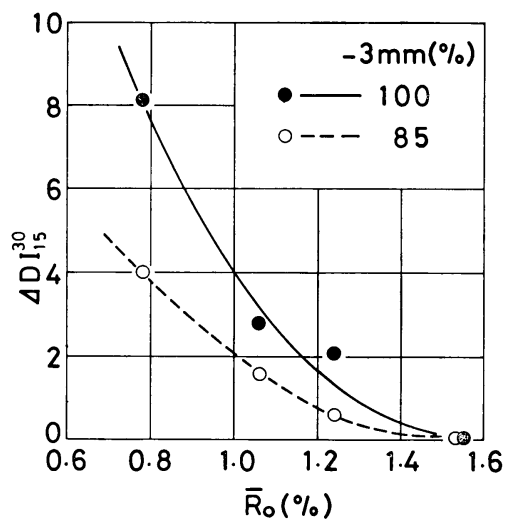

Fig. 3. Influence of reflectance of vitrinite on increase of coke strength by fine crushing (the coke strength of charge crushed to pass $3 \mathrm{~mm}$ sieve by $70 \%$ is regarded as standard).

\subsection{2 種配合炭}

SIMONIS ら2) は 2 種配合炭について, 両石炭の表面積 を同一とする粒度調整が最大のコークス強度を与兄るこ とを実験的に確認した. したがつて，SimONIS らと同一 の結論が理論式から導出されることを証明すればよい.

簡単のために石炭粒子は球であり, 石炭 A, B は単一 粒径 $r_{\mathrm{A}}, r_{\mathrm{B}}$ の粒子で構成され, 両者の密度は同一值 $\rho$ 之 する. 両石炭の配合率を $F_{\mathrm{A}}, F_{\mathrm{B}}\left(=1-F_{\mathrm{A}}\right)$, 融着性パ ラメータを $X_{\mathrm{A}}, X_{\mathrm{B}}$, 石炭化度パラメータを $Y_{\mathrm{A}}, Y_{\mathrm{B}}$ で 表すと, (5) 式は (9)〜(11) 式から,

$$
\bar{S}=S+K\left(F_{\mathrm{B}} r_{\mathrm{A}}^{3}+F_{\mathrm{A}} r_{\mathrm{B}}^{3}\right)
$$

ここに，Kは次式で表される.

$$
\begin{gathered}
K=\frac{\pi \rho F_{\mathrm{A}} F_{\mathrm{B}}}{12 I}\left\{\frac{\partial^{2} S}{\partial X^{2}}\left(X_{\mathrm{A}}-X_{\mathrm{B}}\right)^{2}+2 \frac{\partial^{2} S}{\partial X \partial Y}\right. \\
\left.\left(X_{\mathrm{A}}-X_{\mathrm{B}}\right)\left(Y_{\mathrm{A}}-Y_{\mathrm{B}}\right)+\frac{\partial^{2} S}{\partial Y^{2}}\left(Y_{\mathrm{A}}-Y_{\mathrm{B}}\right)^{2}\right\}
\end{gathered}
$$

平均粒径が一定值 $r_{0}$ である条件は次式で与えられる.

$$
F_{\mathrm{A}} r_{\mathrm{A}}+F_{\mathrm{B}} r_{\mathrm{B}}=r_{0}
$$

細粒化がュークス強度を上昇させる時は，Kは負值であ るから，(19)式の条件下で $F_{\mathrm{B}} r_{\mathrm{A}}{ }^{3}+F_{\mathrm{A}} r_{\mathrm{B}}{ }^{3}$ を最小とすれ ば最大のコークス強度が得られる。

簡単な計算から， $F_{\mathrm{B}} r_{\mathrm{A}}^{3}+F_{\mathrm{A}} r_{\mathrm{B}}^{3}$ を最小とする粒径が

$$
\begin{aligned}
& r_{\mathrm{A}}=r_{0} F_{\mathrm{A}} /\left(F_{\mathrm{A}}^{2}+F_{\mathrm{B}}^{2}\right) \\
& r_{\mathrm{B}}=r_{0} F_{\mathrm{B}} /\left(F_{\mathrm{A}}^{2}+F_{\mathrm{B}}^{2}\right)
\end{aligned}
$$

であることがわかる．この時，配合炭単位重量当たりの 石炭Aの表面積,

$$
4 \pi\left(\frac{r_{\mathrm{A}}}{2}\right)_{4 / 3 \pi\left(r_{\mathrm{A}} / 2\right)^{3} \rho}^{2}=\frac{6\left(F_{\mathrm{A}}^{2}+F_{\mathrm{B}}^{2}\right)}{\rho r_{0}}
$$

之石炭 B の表面積

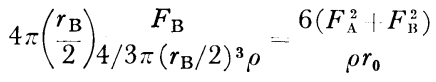

は一致する。

\section{3 多種配合炭}

配合組成が一定の時, $S$ と偏微分係数は定数となる. また，(12)〜 (14) 式中の積分項は尖測叮能な值であるか ら，不均質パラメータを

$$
\begin{aligned}
& D_{\mathrm{XX}, \mathrm{i}}=\int_{0}^{\infty} f_{\mathrm{i}}(r) r^{3}\left\{\bar{X}-X_{\mathrm{i}}(r)\right\}^{2} d r \\
& D_{\mathrm{XY}, \mathrm{i}}=\int_{0}^{\infty} f_{\mathrm{i}}(r) r^{3}\left\{\bar{X}-X_{\mathrm{i}}(r)\right\}\left\{\bar{Y}-Y_{\mathrm{i}}(r)\right\} d r \\
& D_{\mathrm{YY}, \mathrm{i}}=\int_{0}^{\infty} f_{\mathrm{i}}(r) r^{3}\left\{\bar{Y}-Y_{\mathrm{i}}(r)\right\}^{2} d r
\end{aligned}
$$

と定義すると，(5)式は次の上らに変形される.

$$
\begin{aligned}
S=A_{1} & +A_{2} \sum_{\mathrm{i}=1}^{n} F_{\mathrm{i} 0} D_{\mathrm{XX}, \mathrm{i}}+A_{3} \underset{\mathrm{i}=1}{\sum_{1}^{n}} F_{\mathrm{i},} D_{\mathrm{XY}, \mathrm{i}} \\
& +A_{4} \sum_{\mathrm{i}=1}^{n} F_{\mathrm{i} 0} D_{\mathrm{YY}, \mathrm{i}}
\end{aligned}
$$

$$
\left(A_{1} \sim A_{4}\right. \text { : 定数) }
$$

粒度構成のみを変化させた時のコークス強度が上式にし たがえば，理論が検証されたことになる。

配合組成を一定のまま，粒度構成のみを変化させ，小 型レトルト法（JIS-M8801）による乾留り駼を行つた。 (繰り返し 2 回). 配合組成を Table 2 に示寸. 试料石 炭（䊀径：6〜10 mm) はあらかじめ，小型ハンマー・ミ ル (スクリーン・スリット: $7 \mathrm{~mm})$ で粉研し， $P \simeq 75$ 小 よび $90 \%$ の 2 種の粒度水準の試料を作製し全星を即分 けて粒度分布および各粒度区分ごとの $\mathrm{MF}, R_{0}$ を測定し た. Pittston Blend 炭粗确試料の粒度阔特性を Fig. 4 に示す。な技, Balmer 炭と大夕張荻の MF は先測て

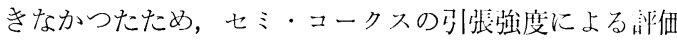
法7をを適用した．各石炭の粒度水準は 2 種であるから配 合炭の粒度構成は $2^{7}$ 通りある。この中から 17 種の粘 度構成を選び，蒿密度を一定 $(0.707 \mathrm{~kg} / l)$ として乾留 した.

Table 2. The composition of blend used in the experiment.

\begin{tabular}{lccc}
\multicolumn{1}{c}{ Coal } & $\begin{array}{c}\mathrm{MF} \\
(\log \mathrm{ddpm})\end{array}$ & $\bar{R}_{\mathbf{0}}(\%)$ & $\begin{array}{c}\text { Blending } \\
\text { Ratio }(\%)\end{array}$ \\
\hline Itmann & 1.33 & 1.53 & 8.7 \\
Pittston Blend & 3.11 & 1.00 & 19.5 \\
Balmer & $-0.03^{*}$ & 1.26 & 18.4 \\
Coal Cliff & 1.12 & 1.13 & 11.6 \\
Wollondilly & 0.88 & 0.93 & 10.0 \\
Newdell & 1.86 & 0.80 & 20.0 \\
Oyubari & $6.09^{*}$ & 0.93 & 11.8 \\
Blend & 2.03 & 1.05 & \\
\hline *estimated value according to the tensile strength measurement & \\
\hline
\end{tabular}




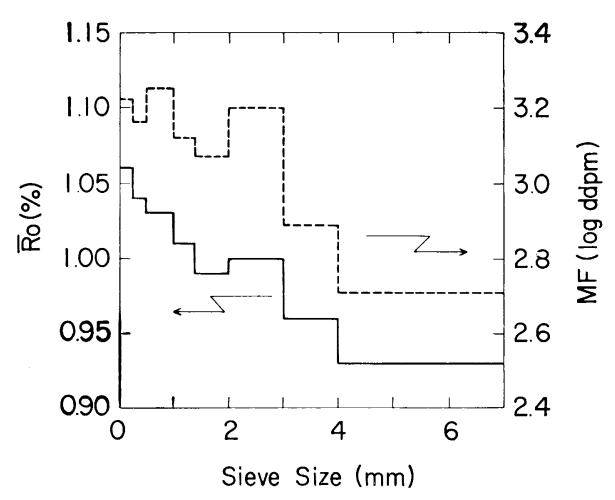

Fig. 4. Effect of diameter of coal on coking properties (Pittston Blend coal, $75 \%$ under $3 \mathrm{~mm}$ sieve).

Table 3. Inhomogeneity, degree of crushing and coke strength of the blends used in the experiment.

\begin{tabular}{|c|c|c|c|c|c|}
\hline \multirow{2}{*}{$\begin{array}{l}\text { Exp. } \\
\text { No. }\end{array}$} & \multicolumn{3}{|c|}{ Inhomogeneity of charge } & \multirow{2}{*}{$-3 \mathrm{~mm} \%$} & \multirow{2}{*}{$\mathrm{DI}_{15}^{30}$} \\
\hline & $l) \times \mathrm{x}$ & $I)_{\mathrm{XY}}$ & $D_{Y Y}$ & & \\
\hline 1 & 109.2 & -5.05 & 1.073 & 74.1 & 87.5 \\
\hline 2 & 104.8 & -4.77 & 0.775 & 77. 1 & 88.8 \\
\hline 3 & 1032 & -4.76 & 1. 049 & 79.2 & 87.8 \\
\hline 4 & 93.3 & -3.86 & 0.700 & 79.3 & 89.0 \\
\hline 5 & 90.9 & -4.43 & 0. 960 & 80.0 & 88.3 \\
\hline 6 & 49.7 & -300 & (). 991 & 80.2 & 89.3 \\
\hline 7 & 104.8 & -4.83 & 0.606 & 80.6 & 89.3 \\
\hline 8 & 102.4 & -5.40 & 0.866 & 81.3 & 89.5 \\
\hline 9 & 48. 2 & -2.37 & 0.732 & 81.4 & 89.0 \\
\hline i) & 93.3 & -3.91 & 0.530 & 82.8 & 88.7 \\
\hline 11 & 91.0 & -4.49 & 0.791 & 83.5 & 88.2 \\
\hline 12 & 48.2 & -2.42 & 0.562 & 84.9 & 89.1 \\
\hline 13 & 45. 9 & -2.99 & 0.822 & 85.5 & 88.8 \\
\hline 14 & 31.4 & -2.38 & 0.878 & 86.1 & 88.6 \\
\hline 15 & 29.9 & -1.76 & 0.619 & 87.3 & 88.2 \\
\hline 16 & 31.4 & -2.43 & 0.708 & 89.6 & 88.6 \\
\hline 17 & 29.9 & i. 81 & 0.449 & 90.8 & 88.5 \\
\hline
\end{tabular}

各粉砕単味苂の $D$ 佔は， $(24) \sim(26)$ 式を $r=0.01 \mathrm{~mm}$ から $7 \mathrm{~mm}$ 史で $0.01 \mathrm{~mm}$ 刻みで数值積分して求めた。 この祭，X(r)，Y(r) はり測值を， $f(r)$ は Rosin-Rammler 式の 1 次臫闺数を用いた。笑験絬果をあとめて Table 3 に亦与.

配仓荻の粘度は $P=74 \sim 91 \%$ と広い範囲にわたつて いる. そこで, 最初に No. 1 9 の比較的狭い粒度範囲 を刘像にして(27)式中の定数を最小白乗法で求め,

$$
\begin{aligned}
\mathrm{DI}_{15}^{30}=92.1- & 0.0627 \sum_{\mathrm{i}=1}^{n} F_{\mathrm{i} 0} D_{\mathrm{XX}, \mathrm{i}} \\
& -1.30 \sum_{\mathrm{i}=1}^{n} F_{\mathrm{i} 0} D_{\mathrm{XY}, \mathrm{i}} \\
& -3.85 \sum_{\mathrm{i}=1}^{n} F_{\mathrm{i} 0} D_{\mathrm{YY}, \mathrm{i}} \cdots
\end{aligned}
$$

の回少式を得た. 上式を No. 10〜17 のデータに適用し たところ, 尖測值よりも高い $\mathrm{DI}_{15}^{30}$ が計算されたが, 推 定残差とPには強い伿相阙が誥められる. (Fig. 5). こ

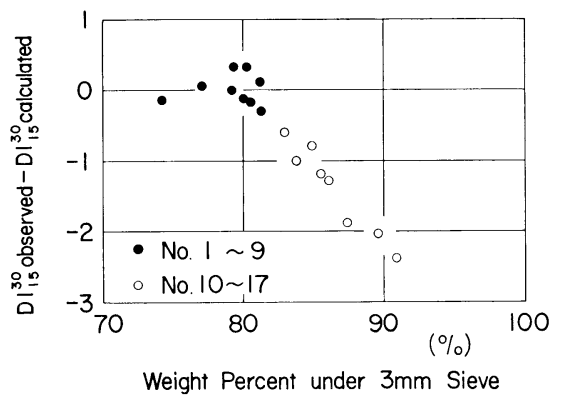

Fig. 5. Relation between crushing degree of blends and error calculated by equation (28) determined by No. $1 \sim 9$ data.

のことは、コークス強度に対する微粉砕の負効果（膨張 性の減少）がPで記述されることを示す。しか，実操 業においては，装入炭のP值はュークス炉の乾留条件に よつてあらかじめ決定されることが多い，この時は，コ 一クス強度に対するPの効果は考虑する必要はなく, 理 論式にしたがつて均質化を進めればよい. (27) 式にPの 2 次式を加え, 全実験データを対象に解析し, 次の回帰 式を得た.

$$
\begin{aligned}
\mathrm{DI}_{15}^{30} & =92.7-0.0734 \sum_{\mathrm{i}=1}^{n} F_{\mathrm{io}} D_{\mathrm{XX}, \mathrm{i}} \\
& -1.54 \sum_{\mathrm{i}=1}^{n} F_{\mathrm{i} \mathrm{O}} D_{\mathrm{XY}, \mathrm{i}} \\
& -4.30 \sum_{\mathrm{i}=1}^{n} F_{\mathrm{io}} D_{\mathrm{XY}, \mathrm{i}}-0.0116(P-74.50)^{2}
\end{aligned}
$$

粒度構成による強度の変動は, 上式でほとんど説明され る (Fig. 6).

\section{5. 実操業への応用}

\section{$5 \cdot 1$ 不均質性パラメータの近似}

理論式を厳密に実操業に適用すれば，D項の算出のた めに多くの分析が必要となり繁雑である. そこで，D項 を少数のパラメータで近似的に表す方法を考える.

Fig. 4 に示したように，石炭の性状は粒径に依存す るが，その変動幅は $\mathrm{MF}$ で $\pm 0.3 ， R_{0}$ で \pm 0.06 程度 であり比較的小さい. したがって，近似的に，

$$
D_{\mathrm{XY}, \mathrm{i}} \simeq\left(\bar{X}-X_{\mathrm{i}}\right)\left(\bar{Y}-Y_{\mathrm{i}}\right) \int_{0}^{\infty} f_{\mathrm{i}}(r) r^{3} d r \cdots
$$

と表される. $\int_{0}^{\infty} f_{\mathrm{i}}(r) r^{3} d r$ は石炭 $\mathrm{i}$ の粒子平均体積に比 例する項であり，Pの多項式で近似される，最も簡単な 形としてPの 1 次式を選び, 微粉化によつて積分值が 0

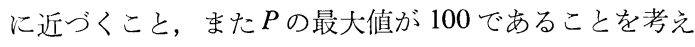
ると, $B$ を正の定数として， 


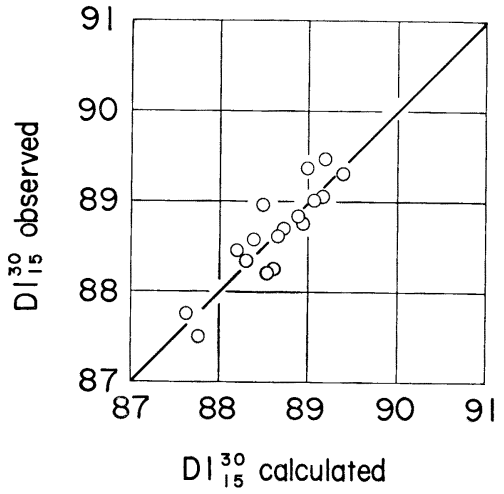

Fig. 6. Correspondence of coke strength calculated by equation (29) to observed one.

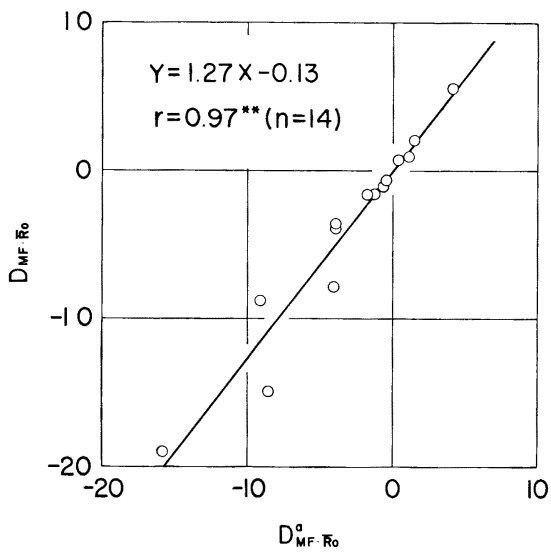

Fig. 7. Relation between inhomogeneity parameter estimated approximately and precise one.

$$
\int_{0}^{\infty} f_{\mathrm{i}}(r) r^{3} d r \simeq B\left(100-P_{\mathrm{i}}\right)
$$

を得る。(30)，(31)式から，

$$
\begin{aligned}
& D_{\mathrm{XY}, \mathrm{i}} \simeq B \cdot\left(\bar{X}-X_{\mathrm{i}}\right)\left(\bar{Y}-X_{\mathrm{i}}\right)\left(100-P_{\mathrm{i}}\right) \\
& \quad \equiv B \cdot D_{\mathrm{X} \mathrm{Y}, \mathrm{i}}^{\mathrm{a}} \ldots \ldots \ldots \ldots \ldots \ldots \ldots \ldots \ldots \ldots \ldots \ldots \ldots \ldots \ldots \ldots \ldots \ldots \ldots \ldots \ldots \ldots \ldots \ldots
\end{aligned}
$$

実際に，4.3 の実験で用いた単味粉砕試料について $D_{\mathrm{XY}, \mathrm{i}}$ と近似值 $D_{\mathrm{X} Y, \mathrm{i}}^{\mathrm{a}}$ 比較すると高度の相関が諗め られ (Fig. 7)， $D_{\mathrm{XY}, \mathrm{i}}$ の代少りに $D_{\mathrm{XY}, \mathrm{i}}^{\mathrm{a}}$ 早いてもよ いことがわかるる。 $D_{\mathrm{XX}, \mathrm{i}} ， D_{\mathrm{YY}, \mathrm{i}}$ も次のように近似され ๖.

$$
\begin{aligned}
& D_{\mathrm{XX}, \mathrm{i}} \simeq B \cdot\left(\bar{X}-X_{\mathrm{i}}\right)^{2}\left(100-P_{\mathrm{i}}\right) \equiv B \cdot D_{\mathrm{XX}, \mathrm{i}}^{\mathrm{a}} \\
& D_{\mathrm{YY}, \mathrm{i}} \simeq B \cdot\left(\bar{Y}-X_{\mathrm{i}}\right)^{2}\left(100-P_{\mathrm{i}}\right) \equiv B \cdot D_{\mathrm{Y} \mathrm{Y}, \mathrm{i}}^{\mathrm{a}}
\end{aligned}
$$

\section{2 偏微分係数値の検討}

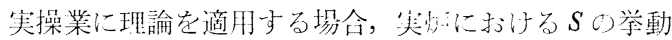

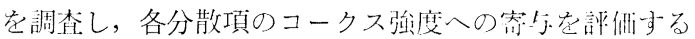
ことが必要である。このため，水出丁場 No. 3,4,5 コ

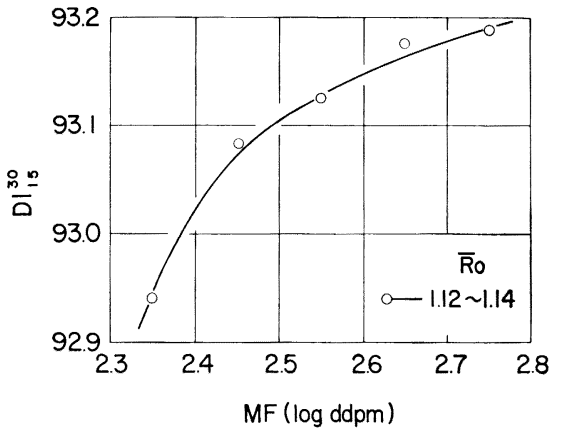

Fig. 8. Relation between coke strength and MF of charge (No. 3, 4 and 5 coke ovens in Mizushima Work).

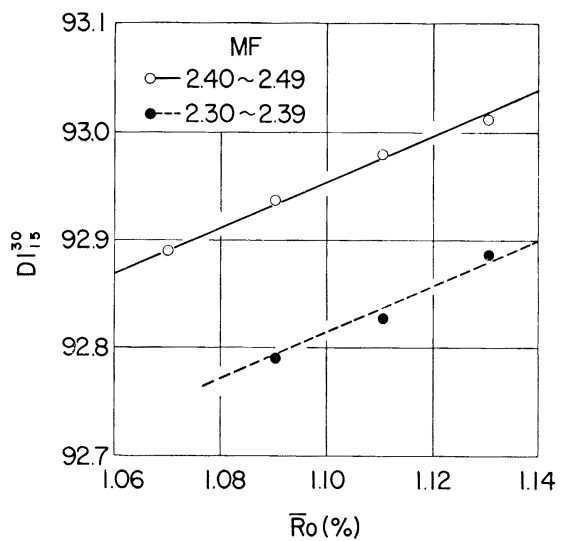

Fig. 9. Relation between coke strength and $R_{0}$ of charge (No. 3, 4 and 5 coke ovens in Mizushima Work).

一クス炉団の実操業データ（昭和 52 年 1 月 54 年3 月）を整理し， $\mathrm{DI}_{15}^{30}$ と $\mathrm{MF}, R_{0}$ の関係を調べた (Fig. $8,9)$. 実操業の配合品位の範囲では, $R_{0}$ に対して $\mathrm{DI}_{15}^{30}$ は直線的に増加し，その勾配は MF 值によらずほぼ一 定である。したがつて，近似的に，

$$
S=S(\mathrm{MF})+b \cdot \bar{R}_{0}(\mathrm{~b}: \text { 定数 })
$$

と表されるから，（5) 式は，(12)，(24)，(33)式を用い て次式となる.

$$
S=S+\frac{\pi B}{12 I} \frac{\partial^{2} S}{\partial X^{2}} \sum_{\mathrm{i}=1}^{n} F_{\mathrm{i} 0}\left(\bar{X}-X_{\mathrm{i}}\right)^{2}\left(100-P_{\mathrm{i}}\right) \cdots
$$

これらの炉団については，(36)式中の $\Sigma$ 項を最小とす るよらに $P_{\mathrm{i}}$ を調整すれば最大のコークス強度が得られ る.この理論粒度調整法はすでに尖操業に適用され，平 均して $\mathrm{DI}_{15}^{30}$ で0.1の向上がそたらされた8)。 また流動 性が不足気味の配合ほど，理論粒度調整法济效果的なこ とが確認されている8). 


\section{6. 結言}

装入炭のコークス強度が加成性のある 2 種のパラメー タで規定されるといら経験則を出発点として，コークス 強度, 装入苂の不均質性および粒度構成の関係について 一般化した理論を構築した. この理論の特長は次の 3 点 に要約される.

（1）従来はあいまいであつた装入炭の不均質性をコ ークス化性因子の分散で定式化した.

（2）分散の一般解を粒度構成の関数として与えた.

（3）コークス強度に対する不均質性の影響が，装入 炭の性状に依存することを定量的に表現した。

単味炭と多種配合炭に対しては, 理論の妥当性を実験 によつて検証した，2種配合炭に対しては, 彷来の均質 化を目標とした粒度調整の考え方を内包する理論である ことが明らかとなつた.これらの実験結果を踏をえて理 論式は近似化され，実操業に適用されている.

\section{Appendix}

$\mathrm{j}$ 番目のブロック内での石焱 $\mathrm{i}$ の重量分率を $F_{\mathrm{i} j}$ とす れば, 各コークス化性パラメータの偏差は,

$$
\begin{aligned}
& \Delta X_{\mathrm{j}}=\sum_{\mathrm{i}=1}^{n}\left(F_{\mathrm{ij}}-F_{\mathrm{io}}\right) X_{\mathrm{i}} \\
& J Y_{\mathrm{i}}=\sum_{\mathrm{i}=1}^{n}\left(F_{\mathrm{ij}}-F_{\mathrm{i} o}\right) Y_{\mathrm{i}}
\end{aligned}
$$

となり，共分散は次式で表される.

$$
\begin{aligned}
& \frac{1}{N} \sum_{\mathrm{j}=1}^{N} J X_{\mathrm{j}} J Y_{\mathrm{j}}=\frac{1}{N} \sum_{\mathrm{j}=1}^{N} \sum_{\mathrm{i}=1}^{n}\left(F_{\mathrm{ij}}-F_{\mathrm{io}}\right)^{2} X_{\mathrm{i}} Y_{\mathrm{i}} \\
& +\frac{1}{N} \sum_{\mathrm{j}=1}^{N} \sum_{\substack{\mathrm{k}=1 \\
\mathrm{k}=1}}^{n} \sum_{\substack{\mathrm{i}=1 \\
n}}^{n}\left(F_{\mathrm{kj}}-F_{\mathrm{ko}}\right)\left(F_{1 \mathrm{j}}-F_{1 \mathrm{o}}\right) X_{\mathrm{k}} Y_{1} .
\end{aligned}
$$

\section{1. 異種石炎に阅する項}

BUSLIK $^{4)}$ と同様に各粒子が十分に小さい体積 $v_{0}$ の単 位から構成されていると考光，石炭 $\mathrm{i} の 1$ 粒子の体積を $v_{\mathrm{i}}$ とする. 1 粒子中の単位の個数 $\left(v_{\mathrm{i}} / v_{0}\right)$ と 1 ブロッ ク中の単位数 $t\left(=I / v_{0}\right)$ は整数と見なせるので，（A3） 式右辺第 2 項は一つの $(\mathrm{k}, \mathrm{l})$ の組について, 次式に変形 される。

$$
\begin{aligned}
& 1 \sum_{\mathrm{j}=1}^{N}\left(F_{\mathrm{kj}}-F_{\mathrm{ko}}\right)\left(F_{1 \mathrm{j}}-F_{10}\right) X_{\mathrm{k}} Y_{1} \\
& =\frac{1}{N t^{2}} X_{\mathrm{k}} Y_{1} \sum_{\mathrm{j}=1}^{N}\left\{\sum_{\mathrm{p}=1}^{t}\left(\delta_{\mathrm{j} \mathrm{p}}^{\mathrm{k}}-F_{\mathrm{ko}}\right)\right\}\left\{\sum_{\mathrm{q}=1}^{t}\left(\delta_{\mathrm{j} \mathrm{q}}^{1}-F_{10}\right)\right\} \\
& =\frac{1}{N t^{2}} X_{\mathrm{k}} Y_{1} \sum_{\mathrm{j}=1}^{N} \sum_{\mathrm{p}=1}^{t}\left(\delta_{\mathrm{j} p}^{\mathrm{k}}-F_{\mathrm{ko}}\right)\left(\delta_{\mathrm{j} \mathrm{p}}^{1}-F_{10}\right)
\end{aligned}
$$

$$
\begin{aligned}
& +\frac{1}{N t^{2}} X_{\mathrm{k}} Y_{1} \sum_{\mathrm{j}=1}^{N} \sum_{\mathrm{p}=1}^{t} \sum_{\mathrm{q}=1}^{t}\left(\delta_{\mathrm{j} p}^{\mathrm{k}}-F_{\mathrm{ko}}\right)\left(\delta_{\mathrm{jq}}^{1}-F_{1 \mathrm{o}}\right) \\
& p \neq q
\end{aligned}
$$

ここに, $\delta_{\mathrm{j} \mathrm{p}}^{\mathrm{k}}$ は $\mathrm{j}$ ブロック中の $\mathrm{p}$ 単位が石炭 $\mathrm{k}$ に属する 時に 1 の值をとり, 他の場合は 0 となると定義された関 数である.

\section{$1 \cdot 1$ 同一単位に関する項}

(A4) 式の右辺第 1 項は, 単位 $\mathrm{p}$ が, $\mathrm{k}, 1$ および $\mathrm{m}$ $(\neq \mathrm{k}, 1)$ 石炭に属する場合に分けて考えると, 次式で与 えられる.

$$
\begin{aligned}
& \frac{1}{N t^{2}} X_{\mathrm{k}} Y_{1} \sum_{\mathrm{j}=1}^{N} \alpha_{\mathrm{jk}} \beta_{\mathrm{k}}\left(1-F_{\mathrm{ko}}\right)\left(-F_{1 \mathrm{o}}\right), \mathrm{p} \in \mathrm{k} \cdots(\mathrm{A} 5) \\
& \frac{1}{N t^{2}} X_{\mathrm{k}} Y_{1} \sum_{\mathrm{j}=1}^{N} \alpha_{\mathrm{j} 1} \beta_{1}\left(-F_{\mathrm{ko}}\right)\left(1-F_{1 \mathrm{o}}\right), \mathrm{p} \in \mathrm{l} \cdots(\mathrm{A} 6) \\
& \frac{1}{N t^{2}} X_{\mathrm{k}} Y_{1} \sum_{\mathrm{j}=1}^{N} \sum_{\substack{\mathrm{m}=1 \\
\mathrm{~m} \neq \mathrm{k}, 1}}^{n} \alpha_{\mathrm{jm}} \beta_{\mathrm{m}}\left(-F_{\mathrm{ko}}\right)\left(-F_{1 \mathrm{o}}\right), \mathrm{p} \in \mathrm{m} \\
&
\end{aligned}
$$

ここに, $\alpha_{\mathrm{jk}}$ は $\mathrm{j}$ ブロック中の $\mathrm{k}$ 石炭の粒子数であり, $\beta_{\mathrm{k}}$ は石岸 $\mathrm{k}$ の粒子 1 個が有する単位の数 $\left(v_{\mathrm{k}} / v_{0}\right)$ であ る. (A 5) （A7) 式点加光，

$$
\sum_{\mathrm{j}=\mathbf{1}}^{N} \alpha_{\mathrm{jk}} \beta_{\mathrm{k}}=\left(N I F_{\mathrm{ko}} / v_{\mathrm{k}}\right)\left(v_{\mathrm{k}} t / I\right)=N t F_{\mathrm{ko}}
$$

の関係を用いると，次式を得る.

$$
\begin{array}{r}
\frac{1}{N t^{2}} X_{\mathrm{k}} Y_{1} \sum_{\mathrm{j}=1}^{N} \sum_{\mathrm{p}=1}^{t}\left(\delta_{\mathrm{j} \mathrm{p}}^{\mathrm{k}}-F_{\mathrm{ko}}\right)\left(\delta_{\mathrm{jp}}^{1}-\Gamma_{10}\right) \\
=-\frac{1}{t} X_{\mathrm{k}} Y_{1} F_{\mathrm{ko}} F_{10} \ldots \ldots \ldots \ldots \ldots \ldots \ldots \ldots \ldots \ldots \ldots \ldots \ldots \ldots
\end{array}
$$

\section{$1 \cdot 2$ 罳なる単位に関する項}

(A4)式右辺第 2 項は, p, q 単位が、互いに買なる石炭 に属する場合と同じ石崖に属する場合に分けて考える. 異なる石炭に属する場合は，( $\left.\delta_{\mathrm{j}}^{\mathrm{k}}-F_{\mathrm{ko}}\right)$ と $\left(\delta_{\mathrm{j}}^{1}-F_{\mathrm{lo}}\right)$ の值は独立であるから， $N$ が十分に大きい時には，積の 平均值はそれぞれの平均值の積で与えられる. 明らかに

$$
\frac{1}{N t} \sum_{\mathrm{j}=1}^{N} \sum_{\mathrm{p}=1}^{t}\left(\delta_{\mathrm{j} \mathrm{p}}^{\mathrm{k}}-F_{\mathrm{ko}}\right)=\frac{1}{N t} \sum_{\mathrm{j}=1}^{N} \sum_{\mathrm{q}=1}^{t}\left(\delta_{\mathrm{j} p}^{1}-F_{10}\right)=0
$$

であるから, 次式を得る。

$$
\frac{1}{N t^{2}} X_{\mathrm{k}} Y_{1} \sum_{\mathrm{j}=1}^{N} \sum_{\substack{\mathrm{p}=1 \\ \mathrm{p} \neq \mathrm{q}=\mathbf{q}}}^{t} \sum_{\substack{\mathrm{j} p \\ \mathrm{k}}}^{t}\left(\delta_{\mathrm{ko}}^{\mathrm{k}}\right)\left(\delta_{\mathrm{j} q}^{1}-F_{1 \mathrm{o}}\right)=0
$$

$\mathrm{p}, \mathrm{q}$ 両単位が同一の石炭に属する時は, その石炭が $\mathrm{k}, \mathrm{l}, \mathrm{m}(\neq \mathrm{k}, 1)$ のいずれであるかによつて， 


$$
\underset{N t^{2}}{1} X_{\mathrm{k}} Y_{1} \sum_{\mathrm{j}=1}^{N} \alpha_{\mathrm{jk}} \beta_{\mathrm{k}}\left(\beta_{\mathrm{k}}-1\right)\left(1-F_{\mathrm{ko}}\right)\left(-F_{1 \mathrm{o}}\right), \mathrm{p}, \mathrm{q} \epsilon \mathrm{k}
$$

$$
\stackrel{1}{N t^{2}} X_{\mathrm{k}} Y_{1} \sum_{\mathrm{j}=1}^{N} \alpha_{\mathrm{j} 1} \beta_{1}\left(\beta_{1}-1\right)\left(1-F_{\mathrm{lo}}\right)\left(-F_{\mathrm{ko}}\right), \mathrm{p}, \mathrm{q} \epsilon \mathrm{l}
$$

$$
\begin{gathered}
\underset{N t^{2}}{1} X_{\mathrm{k}} Y_{1} \sum_{\mathrm{j}=1}^{N} \sum_{\mathrm{m}=1}^{n} \alpha_{\mathrm{jm}} \beta_{\mathrm{m}}\left(\beta_{\mathrm{m}}-1\right)\left(-F_{\mathrm{ko}}\right)\left(-F_{1 \mathrm{o}}\right), \\
\mathrm{p}, \mathrm{q} \in \mathrm{m}
\end{gathered}
$$

の值となる. (A 12)〜 (A 14) 式を加え，

$$
\sum_{\mathrm{j}=1}^{N} \alpha_{\mathrm{jk}} \beta_{\mathrm{k}}^{2}=\left(N I F_{\mathrm{ko}} / v_{\mathrm{k}}\right)\left(v_{\mathrm{k}} t / I\right)^{2}=N t^{2} F_{\mathrm{ko}} v_{\mathrm{k}} / I
$$

を用いて整理すると次式を得る。

$$
\begin{aligned}
& { }^{1} t^{2} X_{\mathrm{k}} Y_{1} \sum_{\mathrm{j}=1}^{N} \sum_{\mathrm{p}=1}^{t} \sum_{\mathrm{q}=1}^{t}\left(\delta_{\mathrm{j} p}^{\mathrm{k}}-F_{\mathrm{ko}}\right)\left(\delta_{\mathrm{jq}}^{\mathrm{l}}-F_{1 \mathrm{o}}\right) \\
& =\frac{1}{I} X_{\mathrm{k}} Y_{1} F_{\mathrm{ko}} F_{10}\left(\sum_{\mathrm{i}=\mathbf{1}}^{n} F_{\mathrm{io}} v_{\mathrm{i}}-v_{\mathrm{k}}-v_{1}\right) \\
& +\frac{1}{t} X_{\mathrm{k}} Y_{1} F_{\mathrm{ko}} F_{1 \mathrm{o}}
\end{aligned}
$$

(A9)，(A11)および(A 16)式を加光， $\mathrm{k} \neq 1$ の条件で和 をとると，次式を得る.

$$
\begin{aligned}
& \frac{1}{N} \sum_{\mathrm{j}=1}^{N} \sum_{\mathrm{k}=1}^{n} \sum_{\mathrm{i}=1}^{n}\left(F_{\mathrm{kj}}-F_{\mathrm{ko}}\right)\left(F_{1 \mathrm{j}}-F_{1 \mathrm{o}}\right) X_{\mathrm{k}} Y_{1} \\
& =\frac{1}{I}\left(\sum_{\mathrm{i}=1}^{n} F_{\mathrm{io}} v_{\mathrm{i}} \sum_{\mathrm{i}=1}^{n} F_{\mathrm{i} \mathrm{o}} X_{\mathrm{i}} \sum_{\mathrm{i}=1}^{n} F_{\mathrm{i} \mathrm{o}} Y_{\mathrm{i}}\right. \\
& -\sum_{\mathrm{i}=1}^{n} F_{\mathrm{io}} v_{\mathrm{i}} \sum_{\mathrm{i}=1}^{n} F_{\mathrm{io}} 2 X_{\mathrm{i}} Y_{\mathrm{i}}-\sum_{\mathrm{i}=1}^{n} F_{\mathrm{i} \mathrm{o}} X_{\mathrm{i}} v_{\mathrm{i}} \sum_{\mathrm{i}=1}^{n} F_{\mathrm{io}} Y_{\mathrm{i}} \\
& \left.-\sum_{\mathrm{i}=1}^{n} F_{\mathrm{io}} X_{\mathrm{i}} \sum_{\mathrm{i}=1}^{n} F_{\mathrm{io}} Y_{\mathrm{i}} v_{\mathrm{i}}+2 \sum_{\mathrm{i}=1}^{n} F_{\mathrm{io}} 2 X_{\mathrm{i}} Y_{\mathrm{i}} v_{\mathrm{i}}\right)
\end{aligned}
$$

\section{2. 同種不炭に関特え项}

BusLiK によれば，次式が求められている.

$$
\begin{aligned}
& \frac{1}{N} \sum_{\mathrm{j}=1}^{N}\left(F_{\mathrm{ij}}-F_{\mathrm{io}}\right)^{2}=\frac{1}{I}\left\{F_{\mathrm{io}}\left(1-F_{\mathrm{io}}\right) v_{\mathrm{i}}+F^{2}{ }_{\mathrm{i} o}\right. \\
& \left.\left(\sum_{\mathrm{k}=1}^{N} F_{\mathrm{ko}} v_{\mathrm{k}}-v_{\mathrm{i}}\right)\right\}
\end{aligned}
$$

上式を用いると(A3) 式右辺第 1 䐜は

$$
\begin{aligned}
& \frac{1}{N} \sum_{\mathrm{j}=1}^{N} \sum_{\mathrm{i}=1}^{n}\left(F_{\mathrm{i} \mathrm{j}}-F_{\mathrm{io}}\right)^{2} X_{\mathrm{i}} Y_{\mathrm{i}} \\
& =\frac{1}{I}\left(\sum_{\mathrm{i}=1}^{n} F_{\mathrm{i} 0} X_{\mathrm{i}} Y_{\mathrm{i}} v_{\mathrm{i}}-2 \sum_{\mathrm{i}=1}^{n} F^{2}{ }_{\mathrm{i},}, X_{\mathrm{i}} Y_{\mathrm{i}} v_{\mathrm{i}}\right. \\
& \left.+\sum_{\mathrm{i}=1}^{n} F^{2_{\mathrm{i} o}} X_{\mathrm{i}} Y_{\mathrm{i}} \sum_{\mathrm{i}=1}^{n} F_{\mathrm{i} 0} v_{\mathrm{i}}\right)
\end{aligned}
$$

となる.（A17)および (A 19)式を (A3) 式に代入し， $\bar{X}$ $=\sum_{\mathrm{i}=1}^{n} F_{\mathrm{i} 0} X_{\mathrm{i}}, \bar{Y}=\sum_{\mathrm{i}=1}^{n} F_{\mathrm{i} 0} Y_{\mathrm{i}}$ を用いて整理すると, 最終 的飞次式を得る。

$$
\left.\frac{1}{N} \sum_{\mathrm{j}=1}^{N} J X_{\mathrm{j}}\right\lrcorner Y_{\mathrm{j}}=\frac{1}{I} \sum_{\mathrm{i}=\mathbf{1}}^{n} F_{\mathrm{i} 0} v_{\mathrm{i}}\left(\bar{X}-X_{\mathrm{i}}\right)\left(\bar{Y}-Y_{\mathrm{i}}\right)
$$

他の分散項も同様にして求められる.

\section{交献}

1) 笑浦義明：燃料協会就，58 (1979), p. 902

2 ) $W$. Simonis, G. Gnuschie, and $K$. G. Beck: Glückauf Forsch. H., 27 (1966), p. 181

3 ) 美浦義明：燃料協会孞，57 (1978), p. 384

4) D. Buslik: ASTM Bulletin, (1950), 165, p. 66

5 ）宮津 降，奥山泰少，鍮木喜夫，福山辰夫，林 融：日本鋼管技報 (1975) 67, p. 125

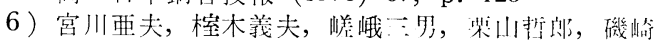
秀夫：コークス・サーキュラー，24 (1975), p. 118

7 ) 杉辺英孝, 宮川要夫：コークス・サーキュラー, 29 (1980), p. 159

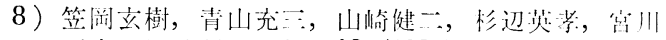
垔夫：川峆製鉄技堿，13(1981)，p. 1 